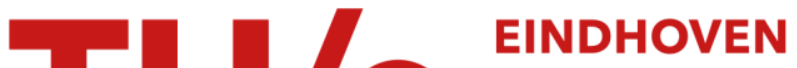 \\ UNIVERSITY OF \\ TECHNOLOGY
}

\section{A model study for coatings containing hexamethoxymethylmelamine}

\section{Citation for published version (APA):}

Meijer, E. W. (1986). A model study for coatings containing hexamethoxymethylmelamine. Journal of Polymer Science, Part A: Polymer Chemistry, 24(9), 2199-2208. https://doi.org/10.1002/pola.1986.080240914

DOI:

10.1002/pola.1986.080240914

Document status and date:

Published: 01/01/1986

\section{Document Version:}

Publisher's PDF, also known as Version of Record (includes final page, issue and volume numbers)

\section{Please check the document version of this publication:}

- A submitted manuscript is the version of the article upon submission and before peer-review. There can be important differences between the submitted version and the official published version of record. People interested in the research are advised to contact the author for the final version of the publication, or visit the $\mathrm{DOI}$ to the publisher's website.

- The final author version and the galley proof are versions of the publication after peer review.

- The final published version features the final layout of the paper including the volume, issue and page numbers.

Link to publication

\section{General rights}

Copyright and moral rights for the publications made accessible in the public portal are retained by the authors and/or other copyright owners and it is a condition of accessing publications that users recognise and abide by the legal requirements associated with these rights.

- Users may download and print one copy of any publication from the public portal for the purpose of private study or research.

- You may not further distribute the material or use it for any profit-making activity or commercial gain

- You may freely distribute the URL identifying the publication in the public portal.

If the publication is distributed under the terms of Article 25fa of the Dutch Copyright Act, indicated by the "Taverne" license above, please follow below link for the End User Agreement:

www.tue.nl/taverne

Take down policy

If you believe that this document breaches copyright please contact us at:

openaccess@tue.nl

providing details and we will investigate your claim. 


\title{
A Model Study for Coatings Containing Hexamethoxymethylmelamine
}

\author{
E. W. MEIJER, Philips Research Laboratories, P.O. Box 80000, \\ Eindhoven, The Netherlands
}

\begin{abstract}
Synopsis
Using a model reaction we have studied the crosslinking chemistry of hydroxy-functional polymers and hexamethoxymethylmelamine. The transetherification of optically active monofunctional alcohols and hexamethoxymethylmelamine was monitored with polarimetry and ${ }^{1} \mathrm{H}-\mathrm{NMR}$. The reaction rate constants for both the forward $\left(k_{1}\right)$ and the backward $\left(k_{-1}\right)$ reaction of the sulphonic-acid-catalyzed alcoholysis were determined. Primary and secondary alcohols showed the same reaction rate and activation energy $\left(E_{a}=96 \mathrm{~kJ} / \mathrm{mol}\right)$ for the forward reaction. However, the backward reaction in the equilibrium is considerably slower for primary alcohols than for secondary alcohols, with activation energies of $E_{a}=96$ and $79 \mathrm{~kJ} / \mathrm{mol}$, respectively. When amine salts of sulphonic acids are used as catalysts, the $E_{\mathrm{a}}$ is increased from 97 to 116 $\mathrm{kJ} / \mathrm{mol}$ in the case of primary alcohols. In concentrated aprotic solutions the reaction order in acid is 2.5. The same order in acid is found for the alcoholysis of acetaldehyde diethyl acetal. All the results strongly support the statement that the crosslinking reaction proceeds by an Sn-1 mechanism. The results of this model study are compared with results obtained in network-forming reactions. The important role of the evaporation of the condensation product methanol is discussed.
\end{abstract}

\section{INTRODUCTION}

Thermoset coatings based on hydroxy-functional resins and melamineformaldehyde crosslinking agents are widely used. Knowledge of the kinetics and mechanism of the crosslinking reaction is of the utmost importance for the understanding of the network structures. This in turn determines the ultimate properties of the coating. Most mechanistic studies have been based on measurements during the formation of the network. ${ }^{1-10}$ High functionality and mixed compositions of the resins and crosslinking agents hampers the elucidation of the mechanism. Therefore, most studies deal with the crosslinking agent hexamethoxymethylmelamine (HMMM). It consists of only one type of functional group, which undergoes under acid conditions only one reaction: transetherification. ${ }^{11}$ Applications of HMMM are found in high-solids coatings. ${ }^{12}$ Although the crosslinking reaction of HMMM and alcohols has been under investigation for about two decades, controversy concerning the mechanism is still prevalent. The overall reaction of HMMM with a hydroxy-functional polymer is given by 


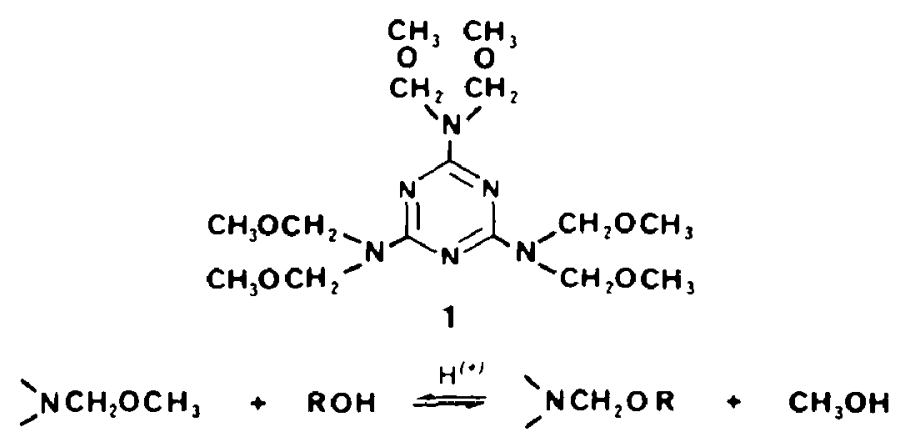

Evaporation of methanol from the film is essential for complete crosslinking. It has been proposed that the specific acid catalyzed reaction proceeds via a carbonium ion. " Support for this statement is given by Bauer and Budde in their study of the crosslinking kinetics of hydroxy-functional acrylates and HMMM. ${ }^{10}$ They determined the extent of the reaction by using infrared spectroscopy. The difference in reactivity of primary and secondary alcohols with HMMM prompted Holmberg to suggest that the reaction must proceed via an $\mathrm{Sn}-2$ mechanism. ${ }^{13}$

An appropriate model study provides detailed information concerning the mechanism of the reaction of HMMM with alcohols in solution. Once the behavior in solution is known the influence of the formation of a polymeric network on the reaction kinetics can be investigated. To date, only one model study has been published indicating that both Sn-1 and Sn-2 occur; the results, however, were misinterpreted. ${ }^{14}$

In this paper the results of the reaction of HMMM and optically active alcohols under acid catalysis are reported. An Sn-1 mechanism is proposed, which clarifies the different kinetics found in the network-forming reactions.

\section{EXPERIMENTAL}

\section{Materials}

Hexamethoxymethylmelamine (Cymel 300, American Cyanamid), 1-2methyl-1-butanol (prim. active Amyl alcohol, Fluka) and d-2-octanol (Aldrich) were used as supplied. Acetaldehyde diethyl acetal (Merck-Schuchardt) was distilled prior to use in order to remove traces of acid. The pyridine salt of 4-dodecylbenzene sulphonic acid was prepared according to a known procedure and purified by crystallization from acetone. ${ }^{15}$ For the kinetic measurements standard mixtures of alcohol and hexamethoxymethylmelamine in dioxane and of $p$-toluene sulphonic acid (or pyridine salt of 4dodecylbenzene sulphonic acid) in dioxane were prepared. The latter was dried over $\mathrm{MgSO}_{4}$ to remove the hydrated water of the acid.

\section{Polarimetry}

Polarimetry is a classical method of quantitative analysis. It consists of measuring the angle of rotation $(\alpha)$ of linearly polarized light. The rotation is caused by the asymmetric chemical structure of the sample, through which a beam of polarized light is passed, and the angle is a linear function of the concentration. When an optically active compound $A$ with $[\alpha]=a$ 
is transformed into another $B$ with $[\alpha]=b$, the observed optical rotation $a=a[A]+b[B]$ is a measure of the extent of the reaction. When reversible first-order reactions are involved the dependence of $a$ with time is given by

$$
\ln \frac{\alpha_{\text {eq }}-\alpha_{0}}{\alpha_{\text {eq }}-\alpha_{t}}=\left(k_{1}+k_{-1}\right) t
$$

in which $\alpha_{\mathrm{eq}}=\alpha$ at equilibrium, $\alpha_{0}=\alpha$ at $t=0$, and $\alpha_{t}=\alpha$ at $t=t$. From the slope of the plot $\ln \left(\alpha_{e q}-\alpha_{t}\right)$ versus time we determined the sum of the forward and backward reaction rate constants $\left(k_{1}+k_{-1}\right)$. For this type of determination it is not necessary to know the absolute angle of rotation for the individual components. A few assumptions have to be made when this technique is used for the reaction of HMMM with optically active alcohols. We have to assume that the angle of rotation is linearly dependent on the concentration of alcohol, [HOR*], and of optically active ether linkages, $\left[\mathrm{NCH}_{2} \mathrm{OR}^{*}\right]$. The latter means that the angle of rotation of one optically active ether group in melamine is not influenced by the introduction of another. It is also necessary to assume that the reactivity of each methoxy group is the same. Thus HMMM has to be regarded as being equivalent to six identical functional groups. The experimental results suggest that these assumptions are reasonable. The measurements were performed in a thermostatted cell compartment of a Perkin-Elmer 144 polarimeter equipped with a chart recorder. The temperature ranged from 50 to $80^{\circ} \mathrm{C}$, and was kept constant within $0.2^{\circ} \mathrm{C}$. The optical rotation at the wavelength of 578 nm was followed with time.

\section{IR and NMR Spectroscopy}

We used infrared and nuclear-magnetic-resonance spectroscopy for the determination of the equilibrium constant, $K_{\mathrm{eq}}=k_{1} / k_{-1}$. When IR is employed, the ratio of absorptions at $\bar{v}=915 \mathrm{~cm}^{-1}\left(\mathrm{CH}_{2} \mathrm{OCH}_{3}\right)$ and $\bar{v}=815$ $\mathrm{cm}^{-1}$ (triazine ring) is characteristic for the extent of the transformation of methoxy groups to alkoxy groups. In duplicate experiments substantial differences were found, probably caused by changes in morphology or film thickness. IR spectra were recorded with a Pye Unicam SP3-300 spectrophotometer. Better results were obtained using ${ }^{1} \mathrm{H}$-NMR spectroscopy. Two pairs of related absorption could be integrated. First, the methoxy group of HMMM $(\delta=3.36 \mathrm{ppm})$ versus the methanol $\mathrm{CH}_{3}$-group $(\delta=3.42 \mathrm{ppm})$. Secondly, the singlet for the methylene group of $>\mathrm{NCH}_{2} \mathrm{OCH}_{3} \quad(\delta=5.12$ ppm) is clearly separated from the methylene group of $>\mathrm{NCH}_{2} \mathrm{OR}^{*}$ $(\delta=5.15 \mathrm{ppm})$. ${ }^{1} \mathrm{H}-\mathrm{NMR}$ spectra were performed with a Bruker WP-80-SY FT spectrometer.

\section{RESULTS AND DISCUSSION}

\section{Primary Versus Secondary Alcohols}

The reaction of hexamethoxymethylmelamine (HMMM) with 1-2-methyl1-butanol as a concentrated solution in dioxane and in the presence of a 


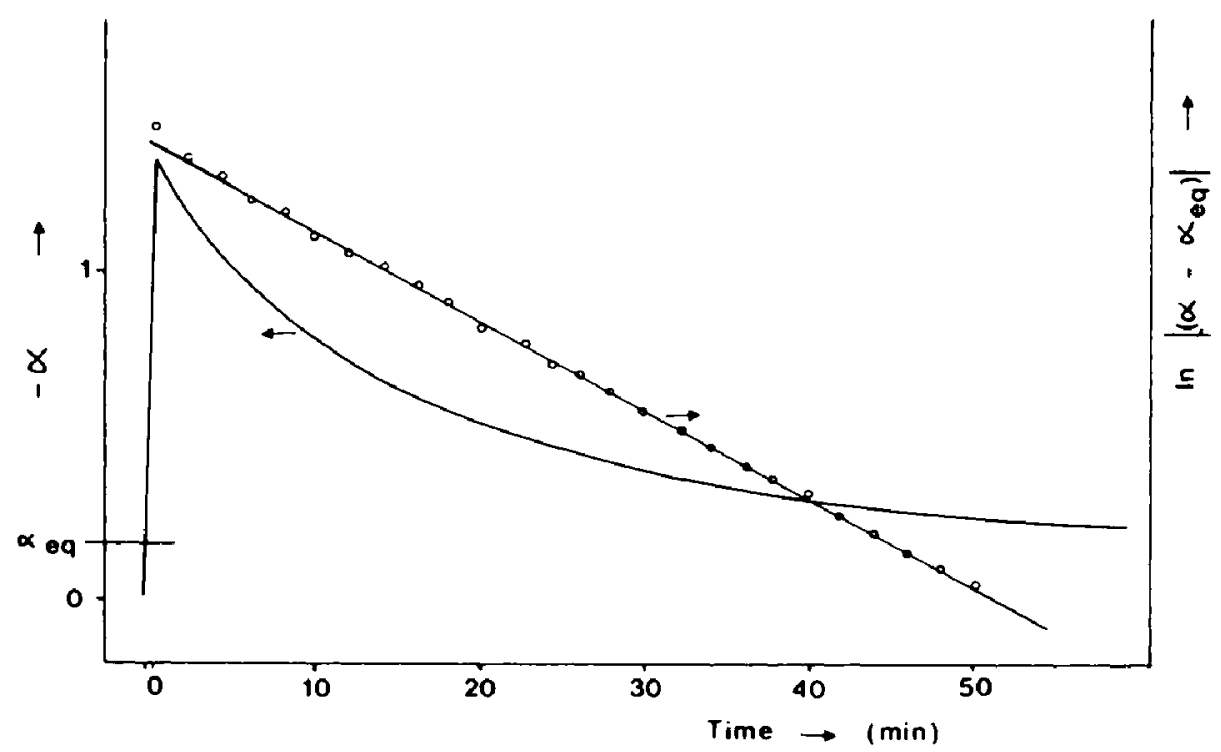

Fig. 1. Plot of the optical rotation $\alpha$ and the $\ln \left(\alpha_{\infty}-a_{\ell}\right)$ vs. the reaction time for a typical experiment.

catalytic amount of $p$-toluene sulphonic acid (PTSA) was studied first. In Figure 1, the optical rotation $\alpha$ is presented as a function of reaction time for a typical experiment. The dependence of $\alpha$ with time clearly obeys the relation for first order reactions, as outlined in the experimental part. In Figure 2 the reaction rate constant $\left(k_{1}+k_{-1}\right)$ is presented as a function of temperature and concentration. The individual rate constants for forward and backward reaction are given in Table I. The methoxy-to-hydroxy ratio was 1. From the slope of the lines we calculated the activation energy to be $E_{a}=96 \mathrm{~kJ} / \mathrm{mol}$. The activation energy appeared to be independent of PTSA concentration. At all temperatures measured the equilibrium constant was established at $K_{\mathrm{eq}}=0.67 \pm 0.1$ indicating $\left|\Delta \mathrm{H}^{\theta}\right|<4 \mathrm{~kJ} / \mathrm{mol}$.

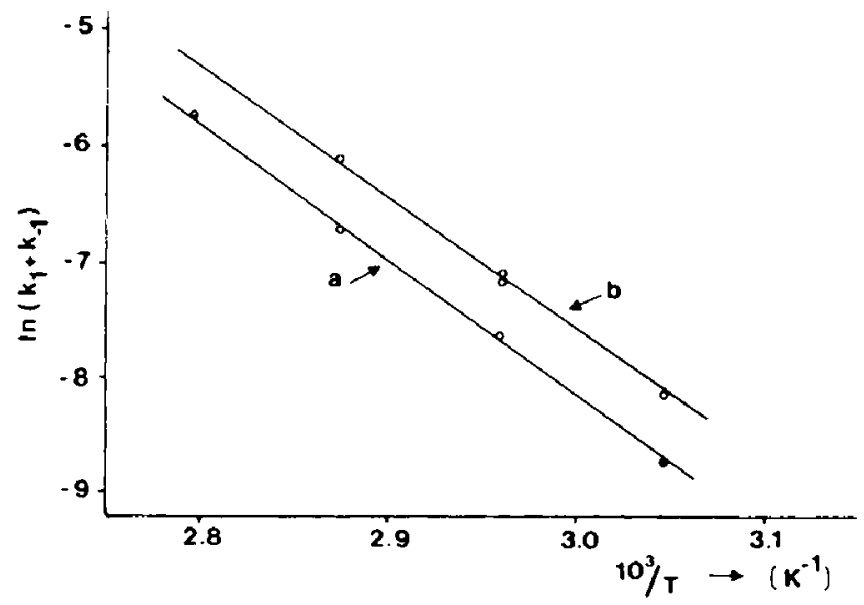

Fig. 2. Plot of the reaction rate constant $\left(k_{1}+k_{-1}\right)$ v8. temperature $(1 / T)$ for the reaction of 1-2-methyl-1-butanol and HMMM in dioxane with PTSA as catalyst (a) [HMMM] $=0.30 M$ / $\mathrm{L} ;[\mathrm{ROH}]=1.78 \mathrm{M} / \mathrm{L} ; \quad[\mathrm{PTSA}]=6.610^{-3} \mathrm{M} / \mathrm{L}$. (b) $[\mathrm{HMMM}]=0.58 \mathrm{M} / \mathrm{L} ;[\mathrm{ROH}]=3.48 \mathrm{M} / \mathrm{L}$; $[\mathrm{PTSA}]=12.910^{-3} \mathrm{M} / \mathrm{L}$. 
TABLE I

Rate Constants and Equilibrium Constants for the Reaction of HMMM and 1-2-methyl-1-butanol under Acid Catalysis

\begin{tabular}{ccccc}
\hline Temp(K) & $K_{\text {eq }}$ & $k_{1+} k_{-1}\left(\mathrm{~s}^{-1}\right)$ & $k_{1}\left(\mathrm{~s}^{-1}\right)$ & $k_{-1}\left(\mathrm{~s}^{1}\right)$ \\
\hline 328.2 & 0.67 & $1.510^{-4}$ & $6.010^{3}$ & $9.010^{-3}$ \\
338.1 & 0.67 & $5.110^{3}$ & $2.110^{-4}$ & $3.110^{-4}$ \\
347.8 & 0.67 & $1.110^{-3}$ & $4.510^{-4}$ & $6.810^{-4}$ \\
358.0 & 0.67 & $3.210^{-3}$ & $1.310^{-3}$ & $1.910^{-3}$ \\
\hline
\end{tabular}

$[\mathrm{HMMM}]=0.30 \mathrm{M} / \mathrm{L} ;[\mathrm{ROH}]=1.78 \mathrm{M} / \mathrm{L} ;[\mathrm{PTSA}]=6.610^{3} \mathrm{M} / \mathrm{L}$

In the next experiment the optically active secondary alcohol, $d$-2-octanol, was used. The results are given in Table II. Arrhenius plots were made for both the forward $\left(k_{1}\right)$ and the backward reaction $\left(k_{-1}\right)$. From the slopes we calculated $E_{a}=96 \mathrm{~kJ} / \mathrm{mol}$ and $E_{\mathrm{a}}=79 \mathrm{~kJ} / \mathrm{mol}$ for $k_{1}$ and $k_{-1}$, respectively. Again the activation energies are independent of acid concentration. The equilibrium is endothermic with $\Delta \mathrm{H}^{\theta}=8 \mathrm{~kJ} / \mathrm{mol}$. Within experimental error the forward reaction rate constants of the secondary alcohol are equal to those of the primary alcohol. However, the reaction rate constants for the backward reaction of the secondary alcohol are substantially larger than those of the primary alcohol.

To compare primary and secondary alcohols it is useful to consider the activation parameters of the reaction of both alcohols with HMMM. These results are presented in Table III (1-2-methyl-1-butanol) and Table IV ( $d$ 2 -octanol). The tabulated values are the average of measurements at two different concentrations of reactants. Again, the activation parameters for the forward reaction of primary and secondary alcohol are equal. These results strongly support an Sn-1 mechanism for the substitution reaction, which proceeds via a carbonium ion or an iminium ion:

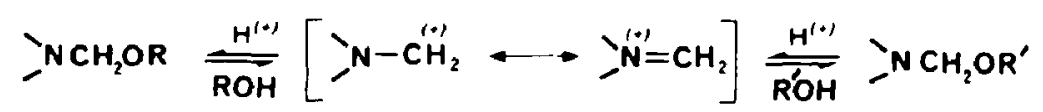

The electronic stabilization of the intermediate ion makes the Sn-1 path feasible. Whether the ion is formed by protonation of the oxygen or of the

TABLE II

Rate Constants and Equilibrium Constants for the Reaction of HMMM and d-2-Octanol under Acid Catalysis

\begin{tabular}{cccccc}
\hline Temp $(\mathrm{K})$ & Concentrations & $k_{\text {eq }}$ & $k_{1+} k_{-1}\left(\mathrm{~s}^{-1}\right)$ & $k_{1}\left(\mathrm{~s}^{-1}\right)$ & $k_{-1}\left(\mathrm{~s}^{-1}\right)$ \\
\hline 328.2 & $\mathrm{~b}$ & 0.11 & $5.310^{-4}$ & $4.910^{-5}$ & $4.710^{-4}$ \\
& $\mathrm{~b}$ & 0.11 & $8.010^{-4}$ & $7.710^{-5}$ & $7.310^{-4}$ \\
338.1 & $\mathrm{~b}$ & 0.13 & $1.210^{-3}$ & $1.410^{-4}$ & $1.110^{-3}$ \\
& $\mathrm{a}$ & 0.13 & $2.010^{-3}$ & $2.210^{-4}$ & $1.810^{-3}$ \\
347.8 & $\mathrm{~b}$ & 0.14 & $2.810^{-3}$ & $3.510^{-4}$ & $2.510^{-3}$ \\
358.0 & $\mathrm{a}$ & 0.14 & $4.110^{-3}$ & $5.210^{-4}$ & $3.610^{-3}$ \\
& $\mathrm{~b}$ & 0.18 & $6.110^{-3}$ & $9.210^{-4}$ & $5.210^{-3}$ \\
& 0.18 & $1.210^{-2}$ & $1.810^{-3}$ & $9.810^{-3}$ \\
\hline
\end{tabular}

- $[\mathrm{HMMM}]=0.23 \mathrm{M} / \mathrm{L} ;[\mathrm{ROH}]=1.38 \mathrm{M} / \mathrm{L} ;[\mathrm{PTSA}]=6.610^{-3} \mathrm{M} / \mathrm{L}$.

${ }^{b}[\mathrm{HMMM}]=0.45 \mathrm{M} / \mathrm{L} ;[\mathrm{ROH}]=2.7 \mathrm{M} / \mathrm{L} ;[\mathrm{PTSA}]=12.910^{-3} \mathrm{M} / \mathrm{L}$. 
TABLE III

Activation Parameters at $298 \mathrm{~K}$ for the Reaction of HMMM and 1-2-methyl-1-butanol under Acid Catalysis

\begin{tabular}{lccc}
\hline \multicolumn{1}{c}{$k$} & $\Delta \mathrm{G}:(\mathrm{kJ} / \mathrm{mol})$ & $\Delta \mathrm{H}:(\mathrm{kJ} / \mathrm{mol})$ & $\Delta \mathrm{S}:(\mathrm{J} / \mathrm{mol} \cdot \mathrm{K})$ \\
\hline$k_{1+} k_{-1}$ & 103 & 90 & -42 \\
$k_{1}$ & 105 & 90 & -50 \\
$k_{-1}$ & 104 & 90 & -46 \\
\hline
\end{tabular}

amino nitrogen external to the ring of the melamine is unclear. It is known from other Sn-1 reactions, that the leaving-group capability increases in the order methanol, 2-methyl-1-butanol, 2-octanol. ${ }^{16}$ This is reflected by the different reaction rate constants and activation parameters found in the reactions of HMMM with alcohols.

\section{Rate Expression of the Reaction}

In order to find the rate expression of the catalyzed reaction of HMMM and 1-2-methyl-1-butanol in dioxane (at the temperature of $65^{\circ} \mathrm{C}$ ) we studied the relation between reaction rate constant and concentration of reactants and catalyst. Since we were interested in a good model for the curing of coatings we studied reactions at high concentration. However, the dependence of reaction rate at high reactant concentration is difficult to investigate in detail. Changes in polarity of the reaction medium will undoubtedly influence the results. A rough estimate indicates that the reaction rate $\left(k_{1}\right.$ $+k_{-1}$ ) is proportional to the reciprocal of the HMMM concentration and to the reciprocal square root of the alcohol concentration. Measurements with different catalyst concentrations in the model reaction are easier to perform. Figure 3 shows that the rate of reaction is proportional to the acid concentration by a power of two and a half. At first sight this result is unexpected and puzzling.

Several questions now arise. Is there a deactivation of the acid by the triazine ring? ${ }^{17}$ Are dicationic species involved? To obtain better insight into this transetherification of alcohols and HMMM, we studied the reaction of 1-2-methyl-1-butanol and acetaldehyde diethyl acetal at the temperature of $65^{\circ} \mathrm{C}$. The hydrolysis of acetals and ketals has been studied in detail and an Sn-1 mechanism is generally accepted. ${ }^{18,19}$ The transetherification is expected to proceed by the same mechanism. In Figure 4 it is shown that a plot of $\left(k_{1}+k_{-1}\right)$ vs. [PTSA] ${ }^{2.5}$ yields a straight line. This result is identical with the reaction of HMMM and 1-2-methyl-1-butanol under the same experimental conditions.

TABLE IV

Activation Parameters at $298 \mathrm{~K}$ for the Reaction of HMMM and $d-2-$ Octanol under Acid Catalysis

\begin{tabular}{lccc}
\hline \multicolumn{1}{c}{$k$} & $\Delta \mathrm{G}:(\mathrm{kJ} / \mathrm{mol})$ & $\Delta \mathrm{H}^{2}(\mathrm{~kJ} / \mathrm{mol})$ & $\Delta \mathrm{S}^{:}(\mathrm{J} / \mathrm{mol} \cdot \mathrm{K})$ \\
\hline$k_{1+} k_{-1}$ & 99 & 79 & -71 \\
$k_{1}$ & 105 & 92 & -50 \\
$k_{-1}$ & 99 & 77 & -75 \\
\hline
\end{tabular}




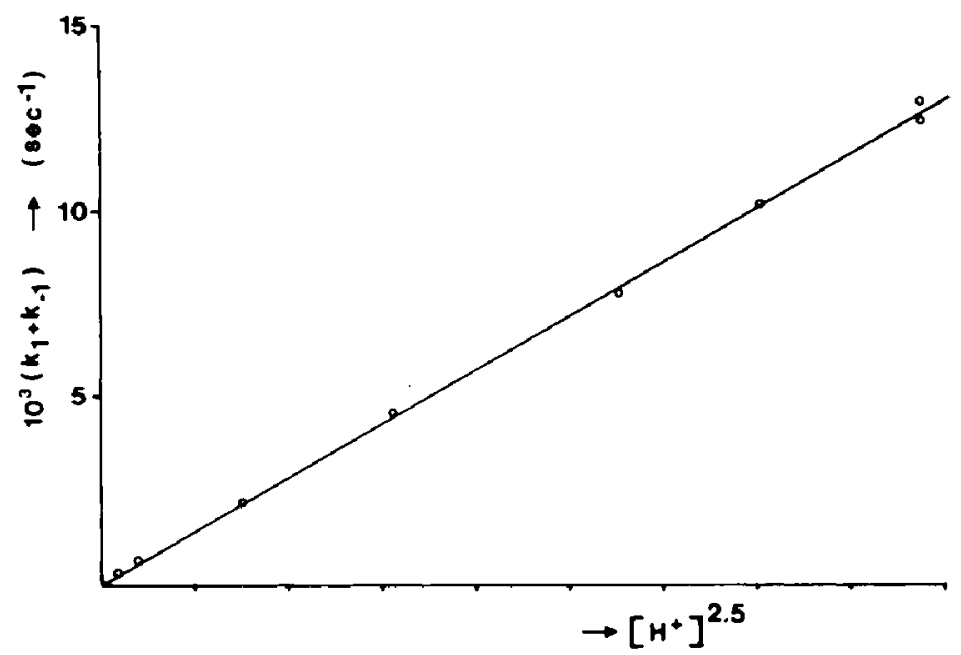

Fig. 3. Plot of the reaction rate constant $\left(k_{1}+k_{-1}\right)$ vs. the PTSA concentration to the power of 2.5 for the reaction of 1-2-methyl-1-butanol and HMMM in dioxane.

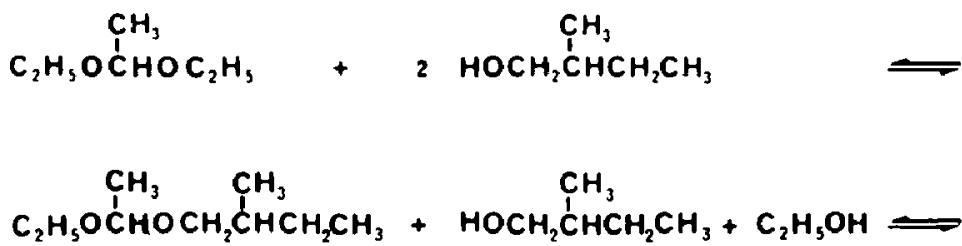<smiles>CCC(C)CC(C)CC(C)CC(C)CC</smiles>

Again, variations in reactant concentrations were difficult to interpret due to polarity changes in the reaction medium. The resemblance between the transetherification of HMMM and acetaldehyde diethyl acetal is striking.

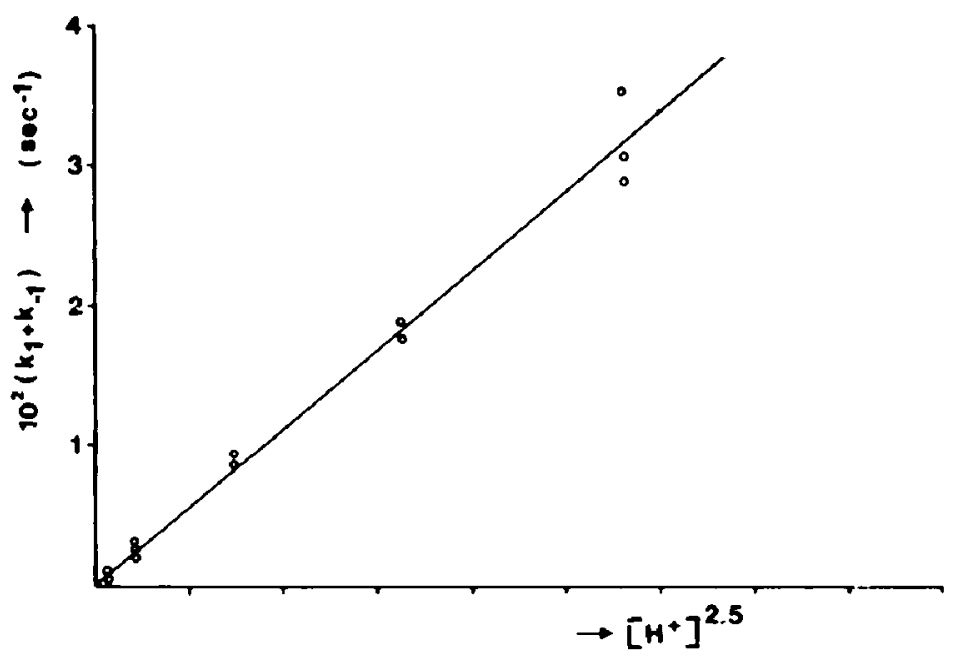

Fig. 4. Plot of the reaction rate constant $\left(k_{1}+k_{-1}\right)$ vs. the PTSA concentration to the power of 2.5 for the reaction of 1-2-methyl-1-butanol and acetaldehyde diethyl acetal in dioxane. 
Obviously the mechanisms are closely related. Hence, it is not expected that the triazine ring will deactivate the acid. A reaction order in acid catalyst between 2 and 3 was observed earlier for several reactions in apolar media. ${ }^{20}$

\section{Latent Catalysts}

Pappas and Hill noted that high $\Delta H^{*}$ and positive $\Delta \mathrm{S}^{*}$ values are demanded for coatings with an excellent potlife in combination with fast cure at low temperatures. ${ }^{21}$ Latent catalysts have to fulfill these requirements. Several experiments were employed to study the difference in catalytic activity between a sulphonic acid and its amine salt in the model reaction. To a 1:1 mixture (on the basis of functional groups) of HMMM and 1-2methyl-1-butanol without solvent was added PTSA (2) or the pyridine salt of 4-dodecylbenzene sulphonic acid (3). From the Arrhenius plots we calculated an increase in $E_{a}$ from $97 \mathrm{~kJ} / \mathrm{mol}$ to $116 \mathrm{~kJ} / \mathrm{mol}$ going from 2 to 3 . Considering the activation parameters for both reactions, we observed a shift in $\Delta \mathrm{H}^{\ddagger}$, whereas for 3 the activation entropy was slightly positive $\left(\Delta \mathrm{S}^{\ddagger}=+29 \mathrm{~J} / \mathrm{mol} \cdot \mathrm{K}\right)$. Extrapolation of the reaction rates indicates that both catalysts possess equal catalytic activity at a temperature of $149^{\circ} \mathrm{C}$. The reactions carried out with different concentrations of 3 indicate that in this case the reaction order in catalyst is between 1 and 2 , contrary to the value of 2.5 for PTSA (2). This result shows that an amine salt of a sulphonic acid fulfils the requirements needed for a latent catalyst.

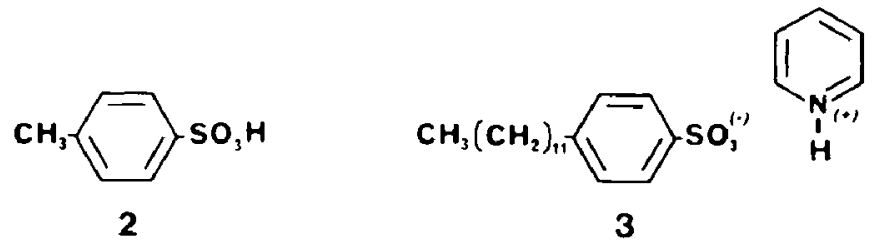

\section{Model Reaction Versus Network-Forming Reaction}

The study of the reactions between HMMM and alcohols presented in this paper is the first model study of the crosslinking of polymers with hydroxyl functional groups and HMMM. Wicks and Hsia published some kinetic data on the transetherification of a model compound for HMMM with tetrahydrofurfural alcohol. ${ }^{14}$ No valid interpretation was given. In their study they monitored the disappearance of a model compound for HMMM as a function of time, when it is brought into reaction with tetrahydrofurfural alcohol. Using two different ratios of $\left[\mathrm{NCH}_{2} \mathrm{OCH}_{3}\right]$ : $[\mathrm{ROH}]$, to wit $1: 1$ and $1: 3$, they found that the difference in rate of disappearance of the model compound for both runs at all time intervals was given by a factor of approximately 1.5. They concluded that this result supports a mechanism in which both $\mathrm{Sn}-1$ and $\mathrm{Sn}-2$ reactions are occurring. However, from our results it is clear that at equilibrium the disappearance of the model compound will be $44 \%$ and $68 \%$, respectively. The difference is a factor of 1.55 and since the equilibrium will be reached for both runs at the same time, this factor of 1.55 will be found at all time intervals. Hence, 
contrary to the interpretation of Wicks and Hsia, their results support an Sn-1 mechanism.

With the knowledge of the mechanism of the reaction between HMMM and alcohols in solution, it is worthwhile studying the influence of the simultaneous formation of a polymer network on the reaction kinetics. The film formation of polyols and HMMM has been studied by several groups leading to the following conclusions: (a) the reaction is specific acid catalyzed, ${ }^{11}$ (b) polymers with primary hydroxyl functional groups react faster than polymers with secondary hydroxyl groups, ${ }^{5,22,23}$ (c) for the PTSA catalyzed reaction $E_{a}=52 \mathrm{~kJ} / \mathrm{mol}$, whereas $E_{a}=88 \mathrm{~kJ} / \mathrm{mol}$ when a PTSA amine salt is used, ${ }^{10}$ (d) the rate constant in the film formation is proportional to the acid concentration, ${ }^{10}$ (e) an increase in hydroxyl value of the polymer leads to faster curing and harder films, ${ }^{13,23}$ (f) hexabutoxymethylmelamine (HBMM) reacts more slowly than HMMM. ${ }^{23}$

At first sight some of these results contradict the results of our model study. However, we propose that during network formation the rate determining step is the result of a combination of reaction rate and evaporation rate and evaporation rate of the condensation product methanol. The role of the latter has always been under-estimated, expecially in thin films. Our study indicates clearly the importance of the evaporation rate in crosslinking reactions where equilibria are involved. The evaporation rate is diffusion controlled and concentration dependent. The diffusion will be hampered due to interactions between methanol and resin. When the methanol is not evaporated immediately the backward reaction will determine the extent of the reaction. Hence, polymers with primary alcohols react faster than polymers with secondary alcohols.

The importance of the evaporation rate is also shown by the comparison of HBMM and HMMM in the same crosslinking reaction. Despite the expected faster forward reaction of HBMM and an equilibrium constant of almost unity, the crosslinking is slower for HBMM. Obviously the slow diffusion of $n$-butanol (compared to methanol) is involved. Finally, the difference in activation energy for the model reaction and the film forming are plausible when the role of the evaporation rate is taken into account.

\section{CONCLUSIONS}

In this paper we have presented a model study for the crosslinking of coatings consisting of hydroxy-functional polymers and hexamethoxymethylmelamine as crosslinking agent. The kinetics of this acid-catalyzed reaction were established with polarimetry. This technique was found to be very suitable for studies of the influence of several catalysts and different reactants on the rate of the crosslinking reaction. To the best of our knowledge it is the first time this polarimetry technique has been applied for kinetic measurements in polymer chemistry. The model reaction strongly supports an Sn-1 mechanism for the transetherification of HMMM. The differences observed in the reaction rates of primary and secondary alcohols were due to the differences in leaving group capability of the alcohols. The substitution reaction proceeds via an intermediate (carbonium or iminium) ion. The electronic stabilization of this ion makes the Sn-1 path feasible. 
Substantial differences in kinetics are observed when the model reaction is compared with a film-forming reaction. We propose that the slow evaporation of the condensation product is partly rate determining for the crosslinking reaction. This study proves that the elucidation of a crosslinking reaction is only possible with low-molecular-weight components avoiding the formation of a polymer network. Once this mechanism is known, the role of the polymer network on the reaction kinetics can be determined.

\section{References}

1. D. R. Bauer and R. A. Dickie, J. Polym. Sci. Polym. Phys. Ed., 18, 1997 (1980).

2. D. R. Bauer and R. A. Dickie, J. Polym. Sci. Polym. Phys. Ed., 18, 2015 (1980).

3. J. Dörffel, Farbe Lack, 88 (1), 6 (1982).

4. R. Saxon and F. C. Lestienne, J. Appl. Polym. Sci., 8, 475 (1964).

5. U. Biethan, K. H. Hornung, and G. Peitscher, Chem Zeit., 96, 208 (1972).

6. J. O. Santer and G. J. Anderson, J. Coat. Technol., 52(667), 33 (1980).

7. J. N. Koral and J. C. Petropoulos, J. Paint. Technol., 38(501), 600 (1966).

8. R. Buter, Farbe Lack, 86(4), 308 (1980).

9. D. R. Bauer and G. F. Budde, Ind. Eng. Chem. Prod. Res. Devel., 20,674 (1981).

10. D. R. Bauer and G. F. Budde, J. Appl. Polym. Sci., 28, 253 (1983).

11. W. J. Blank, J. Coat. Technol, 51(656), 61 (1979).

12. L. W. Hill and Z. W. Wicks, Jr., Prog. Org. Coat., 10, 55 (1982).

13. K. Holmberg, J. Oil. Chem. Assoc., 61, 359 (1978).

14. Z. W. Wicks, Jr. and D. Y. Y. Hsia, J. Coat. Technol., 55(702), 29 (1983).

15. R. Sterzycki, Synthesis, 1879, 724.

16. Skrabel and Eger, Z. Phys. Chem., 122, 349 (1926).

17. A. Berge, B. Kvaeven, and J. Ugelstad, Eur. Polym. J., 6, 981 (1970).

18. E. H. Cordes and H. G. Bull, Chem. Rev., 74, 581 (1974).

19. E. H. Cordes, Prog. Phys. Org. Chem., 4, 1 (1967).

20. L. P. Hammett, Physical Organic Chemistry, (McGraw-Hill, New York, 1940).

21. S. P. Pappas and L. W. Hill, J. Coat. Technol., 53(675), 43 (1981).

22. W. Zimmt, M. Lazzara, C. Senkler, and J. Collette, Proceedings of the Ninth International Conference in Organic Coating Science and Technology, Athens, 1983, p. 301.

23. J. W. Lorimar, J. Paint. Technol., 40, 586 (1968).

Received July 15,1985

Accepted October 18, 1985 